\title{
Excessive Heating
}

National Cancer Institute

\section{Source}

National Cancer Institute. Excessive Heating. NCI Thesaurus. Code C133576.

Problem associated with the device which has a warming or heating function, and is producing excessive heat. 